\title{
Wawasan Pendidikan : Studi Komparatif Sistem Pendidikan Di Beberapa Negara Maju ( Korea Selatan dan Jepang)
}

\author{
Citra Kurniawan \\ Sekolah Tinggi Teknik Malang \\ airakurniawan@gmail.com
}

\section{PENDAHULUAN}

Setiap negara mengembangkan sistem pendidikan dengan tujuan untuk meningkatkan kualitas kehidupan penduduk. Keyakinan akan pentingnya pendidikan yang dapat mengubah peradapan manusia kepada pembentukan sistem pendidikan dirasa dapat menjadi sarana untuk usaha pencapaian tujuan - tujuan pendidikan. Saat ini jika dilihat dari berbagai sistem pendidikan di dunia terdapat kesamaan dalam hal prinsip pendidikan meskipun terdapat perbedaan di berbagai tingkatan dan teknis pelaksanaan.

Semakin berkembangnya ilmu pengetahuan dan teknologi berbagai negara dengan tingkat perkembangan yang berbeda secara tidak langsung mempengaruhi perkembangan sistem pendidikan di masing - masing negara. Diperlukan sebuah kesadaran untuk melakukan studi komparatif terhadap sistem pendidikan berbagai negara sebagai upaya untuk membandingkan sistem pendidikan yang ada dengan sistem pendidikan yang lainnya. Dengan adanya studi komparatif maka diharapkan dapat memberikan kontribusi terhadap perkembangan dan perbaikan pendidikan. Studi komparatif ini selain digunakan untuk kaji banding, juga digunakan untuk melakukan penilaian terhadap komponen dari sistem pendidikan suatu negara.

Dalam makalah ini, penulis mencoba untuk melakukan penilaian terhadap beberapa negara maju jika dilihat dalam dari sistem pendidikan yang berlaku. Proses penilaian ini bertujuan untuk mengkaji perbedaan berdasarkan prinsip studi perbandingan dan memberikan deskripsi sebagai hasil yang diharapkan menjadi kontribusi sebagai saran untuk perkembangan sistem pendidikan di Indonesia yang lebih baik.

\section{PEMBAHASAN}

Sistem pendidikan dari suatu negara tidak lepas dari perkembangan kebudayaan sosial dan lingkungan masyarakat. Oleh sebab itu maka sistem pendidikan dalam setiap negara memiliki perbedaan. Perbedaan sistem pendidikan ini dipengaruhi oleh sistem di masyarakat terhadap pendidikan. Masyarakat atau warga negara atau peserta didik sebagai komponen dalam hubungan supra sistem, berperan sebagai input dalam proses transformasi sistem, pemecah masalah sehingga menghasilkan lulusan yang baik, ilmu pengetahuan baru dan pengembangan kebudayaan. Hubungan sistem pendidikan dengan masyarakat sebagai supra sistem dijelaskan oleh Muhammad Dimyati (1988) pada Gambar 1 berikut :

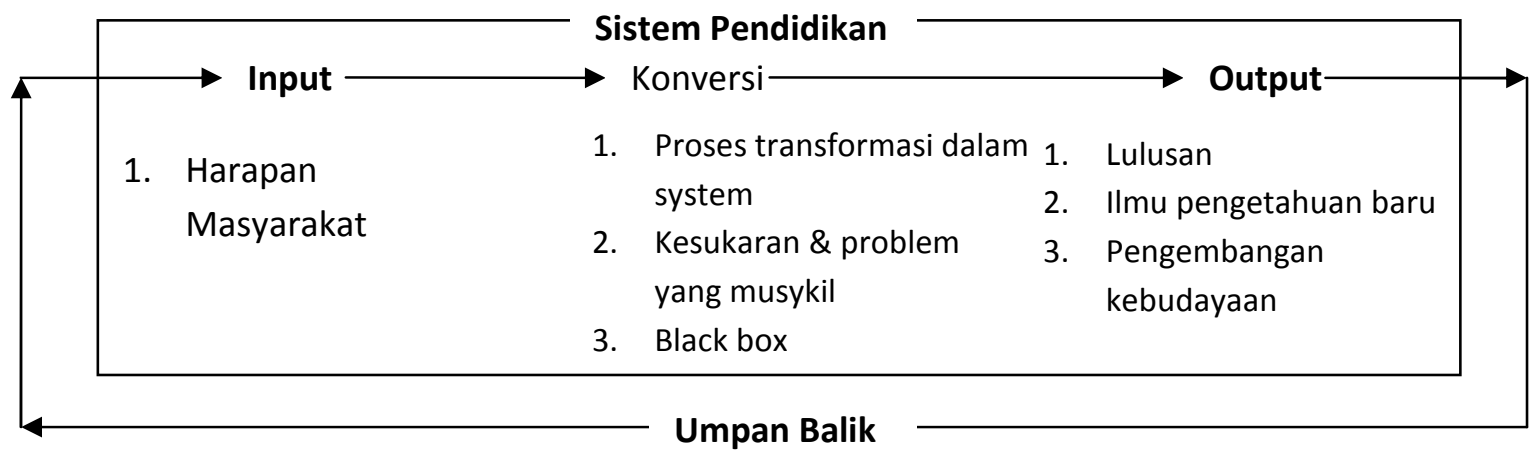

Gambar 1. Hubungan sistem pendidikan dengan masyarakat sebagai supra sistem (Sumber : Muhammad Dimyati,1988) 
Berdasarkan analisis sistem, sistem pendidikan dapat dipahami sebagai keseluruhan. Integrasi dan kesatuan tindak yang dinamis. Sebuah sistem sekolah adalah gambaran yang tepat dan lengkap untuk tentang sistem pendidikan karena sistem sekolah memiliki komponen - komponen saling berhubungan yang berakibat pada pencapaian tujuan pendidikan sekolah. Sistem sekolah mengalami proses transformasi berdasarkan input dari masyarakat, berupa proses belajar mengajar yang merupakan proses fundamental tentang transformasi muatan pendidikan.

Sistem sekolah dalam implementasi sistem pendidikan terdiri dari tiga sub sistem yaitu sub sistem sosial, sub sistem kebudayaan, dan sub sistem ekonomi (Dimyati, 1988). Ketiga komponen tersebut sangat berpengaruh dalam pembentukan landasan terhadap sistem pendidikan. Dalam sub sistem sosial, struktur formal mengatur komunikasi dan interaksi sosial antara guru, administrasi dan siswa. Hubungan antar komponen dalam sub sistem sosial ini berisi jaringan hubungan siswa dengan siswa, hubungan guru dengan siswa, hubungan guru dengan guru dalam bentuk formal atau informal. Jaringan hubungan tersebut secara langsung dan tidak langsung berpengaruh terhadap pencapaian tujuan sekolah.

Selain sub sistem sosial, sistem sekolah juga memiliki sub sistem kebudayaan. Sub sistem kebudayaan merupakan jaringan komples tentang tujuan - tujuan, nilai , tradisi, kepercayaan, cara berpikir, dan perilaku yang berbeda, Indexbeda. Sub sistem kebudayaan pada sekolah terlihat pada adanya komponen berupa tujuan sistem pendidikan sekolah, kurikulum, metodologi, media pengajaran, buku dan materi ajar. Sedangkan pada sub sistem ekonomi, sistem sekolah melakukan prinsip, Indexprinsip ekonomi dalam setiap program dengan meperhitungkan dana, alokasi dan penggunaan sumber, efisiensi penggunaan sumber, produk sistem sekolah dan seleksi. Ketiga sub sistem di atas dipergunakan sebagai upaya untuk mendukung pencapaian tujuan sekolah dalam konteks sistem pendidikan.

Dari hubungan sistem di atas maka dapat dilihat bahwa perkembangan sebuah sistem di pendidikan di suatu negara secara tidak langsung dipengaruhi oleh interaksi sosial, kebudayaan dan ekonomi. Ketiga aspek tersebut perlu dideskripsikan hubungan dan pengaruhnya terhadap sistem pendidikan pada hasil - hasil penilaian pendidikan di beberapa negara maju. Dimensi ekonomi masyarakat adalah salah satu dimensi kehidupan yang memuat pola produksi, distribusi, dan konsumi individu serta kelompok dalam rangka mencapai kemakmuran. Dimensi ekonomi memuat sebuah variabel ekonomi internal dan variabel eksternal (Rohman, 2010). Variabel internal ekonomi berupa regulasi ekonomi yang efektif, keluasan jaringan, ketercukupan modal, adopsi teknologi, tenaga kerja terampil dan insfrastruktur perbankan yang mendukung. Sedangkan variabel ekonomi eksternal adalah berupa iklim usaha kondusif, sistem politik yang stabil, keamanan yang terjamin dan sistem penyelenggaraan pendidikan bermutu. Dari dua variabel tersebut di atas maka dimensi ekonomi dan dimensi pendidikan saling terkait meskipun tidak dapat dipungkiri bahwa kewenangan pemerintah dalam mengatur sebuah kebijakan sistem pendidikan menjadi salah satu faktor penentu kemajuan sistem pendidikan suatu negara.

\section{DESKRIPSI TINGKAT PENDIDIKAN DI BERBAGAI NEGARA}

Dengan semakin meningkatnya upaya pendidikan pendidikan internasional yang bertujuan untuk mewujudkan kehidupan dunia yang lebih harmonis, maka setiap negara mencoba untuk melibatkan ahli - ahli dari banyak negara untuk melakukan penelitian terhadap sistem pendidikan dan keadaan negara lain. Setiap negara mencoba untuk terlibat aktif dalam upaya mewujudkan kehidupan yang saling menghargai melalui pendidikan internasional.

Saat ini berbagai negara semakin bersaing untuk meningkatkan kualitas pendidikan dengan mengaktulisasikan sistem pendidikan. Setiap negara mencoba untuk melakukan pembangunan fisik dan non fisik dalam bidang pendidikan. Berbagai upaya 
dilakukan melalui rekonstruksi fondasi filosofi dan ideologi, revisi orientasi, penyempurnaan organisasi dan perbaikan operasionalnya. Dalam tingkatan pendidikan di negara - negara di dunia, seringkali urutan prestasi sistem pendidikan menjadi acuan untuk menentukan negara, Index negara mana yang termasuk dalam kategori negara dengan pendidikan yang maju. Berikut urutan sistem pendidikan dalam berbagai negara.

Tabel 1. Urutan tingkat index sistem pendidikan negera di dunia 2014

\begin{tabular}{|c|c|c|c|c|}
\hline No & Country & Overall & Cognitive Skills & Educational Attainment \\
\hline 1 & South Korea & Rank 1, Index 1.30 & Rank 2, Index 1.35 & Rank 1, Index 1.19 \\
\hline 2 & Japan & Rank 2, Index 1.03 & Rank 4, Index 1.20 & Rank 6, Index 0.70 \\
\hline 3 & Singapore & Rank 3, Index 0.99 & Rank 1, Index 1.65 & Rank 33, Index 0.33* \\
\hline 4 & Hong Kong - China & Rank 4, Index 0.96 & Rank 3, Index 1.34 & Rank 18, Index 0.20* \\
\hline 5 & Finland & Rank 5, Index 0.92 & Rank 5, Index 0.99 & Rank 4, Index 0.79 \\
\hline 6 & United Kingdom & Rank 6, Index 0.67 & Rank 8, Index 0.52 & Rank 2, Index 0.96 \\
\hline 7 & Canada & Rank 7, Index 0.60 & Rank 6, Index 0.77 & Rank 15, Index 0.25 \\
\hline 8 & Netherlands & Rank 8, Index 0.58 & Rank 7, Index 0.57 & Rank 7, Index 0.58 \\
\hline 9 & Ireland & Rank 9, Index 0.51 & Rank 10, Index 0.49 & Rank 10, Index 0.55 \\
\hline 10 & Poland & Rank 10, Index 0.50 & Rank 16, Index 0.33 & Rank 3, Index 0.85 \\
\hline 11 & Denmark & Rank 11, Index 0.46 & Rank 17, Index 0.32 & Rank 5, Index 0.75 \\
\hline 12 & Germany & Rank 12, Index 0.41 & Rank 12, Index 0.48 & Rank 14, Index 0.28 \\
\hline 13 & Russia & Rank 13, Index 0.40 & Rank 9, Index 0.50 & Rank 21, Index 0.19* \\
\hline 14 & United States & Rank 14, Index 0.39 & Rank 11, Index 0.49 & Rank 20, Index 0.19 \\
\hline 15 & Australia & Rank 15, Index 0.38 & Rank 13, Index 0.43 & Rank 13, Index 0.29 \\
\hline
\end{tabular}

*Dikarenakan banyaknya variasi untuk mengukur tingkat rata-rata kelulusan, maka menggunakan data kelulusan OECD (Organisation for Economic Co- operation and Development).

(Sumber : The Learning Curve - Pearson PLC)

Dari tabel 1 di atas dapat dilihat bahwa penentuan urutan sistem pendidikan di dasarkan pada nilai Cognitive Skilss dan Educational Attainment (Detail urutan tingkat pendidikan dapat dilihat pada Lampiran 1). Penelitian ini dilakukan oleh Pearson PLC pada tahun 2014 yang menempatkan Korea Utara sebagai posisi teratas kemudian disusul oleh Japan, Singapura dan seterusnya. Dalam periode tahun, posisi sistem pendidikan dapat berubah - ubah karena setiap negara selalu berusaha untuk memperbaiki sistem pendidikannya. Jika dilihat dari komposisi urutan tingkat sistem pendidikan maka dapat dilihat bahwa negara dengan tingkat perekonomian dan teknologi maju, tidak secara langsung menduduki peringkat pertama dalam hal sistem pendidikan. Sebagai contoh Korea Selatan, berdasarkan tabel 1, tingkat pendidikannya menduduki peringkat ke-1. Berikut data detail Korea Selatan dapat dilihat pada Gambar 2 Berikut :

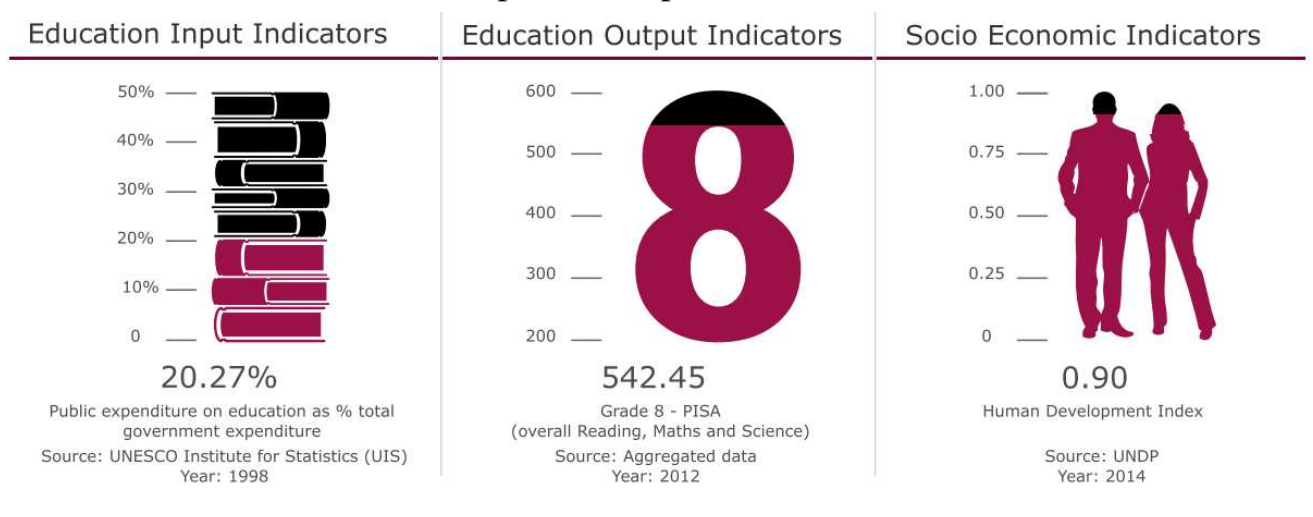




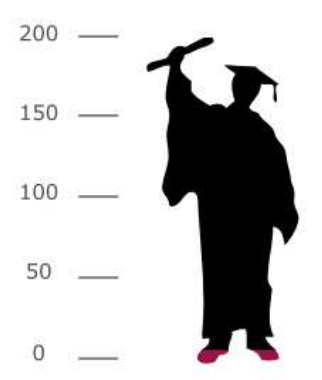

$12.17 \%$

Public expenditure per pupil as \% GDP per capita. Tertiary

Source: UNESCO Institute for Statistics (UIS)

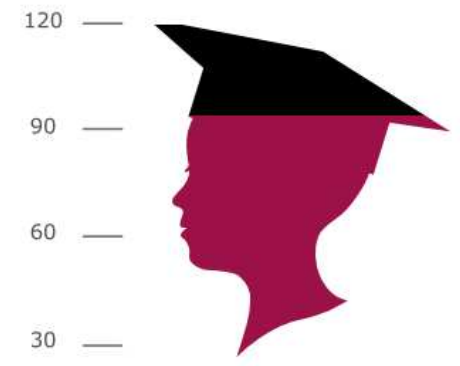

92.00

Graduation rate at upper secondary level

Source: OECD, Education at a Glance

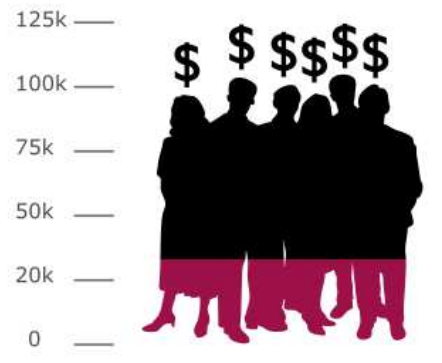

$\$ 34,595.80$

GDP per capita (US\$PPP)

Source: EIU Year: 2014

Gambar 2. Profil Negara Korea Selatan (Sumber : The Learning Curve - Pearson PLC)

Dari Gambar 2, dapat dilihat bahwa indikator Input pendidikan Korea Selatan (Pengeluaran publik pada pendidikan dari total pengeluaran pemerintah) mencapai $20,27 \%$ dengan indikator output pendidikan 542, 45. Korea selatan mempunyai GDP (Gross Domestic Product) per kapita sebesar \$34.595,90. Jika dibandingkan dengan Amerika Serikat dimana pada menduduki urutan ke-14 sistem pendidikannya, mengalokasikan $12,91 \%$ pengeluaran publik pada pendidikan dari total pengeluaran pemerintah sebagai indikator Input pendidikan dengan indikator output pendidikan 492,12. Jika dilihat dari alokasi tersebut maka alokasi pendidikan Amerika Serikat sangat kecil dibandingkan perolehan GDP (Gross Domestic Product) per kapita sebesar \$54.411,70. Indikator Amerika Serikat dapat dilihat pada Gambar 3 berikut :

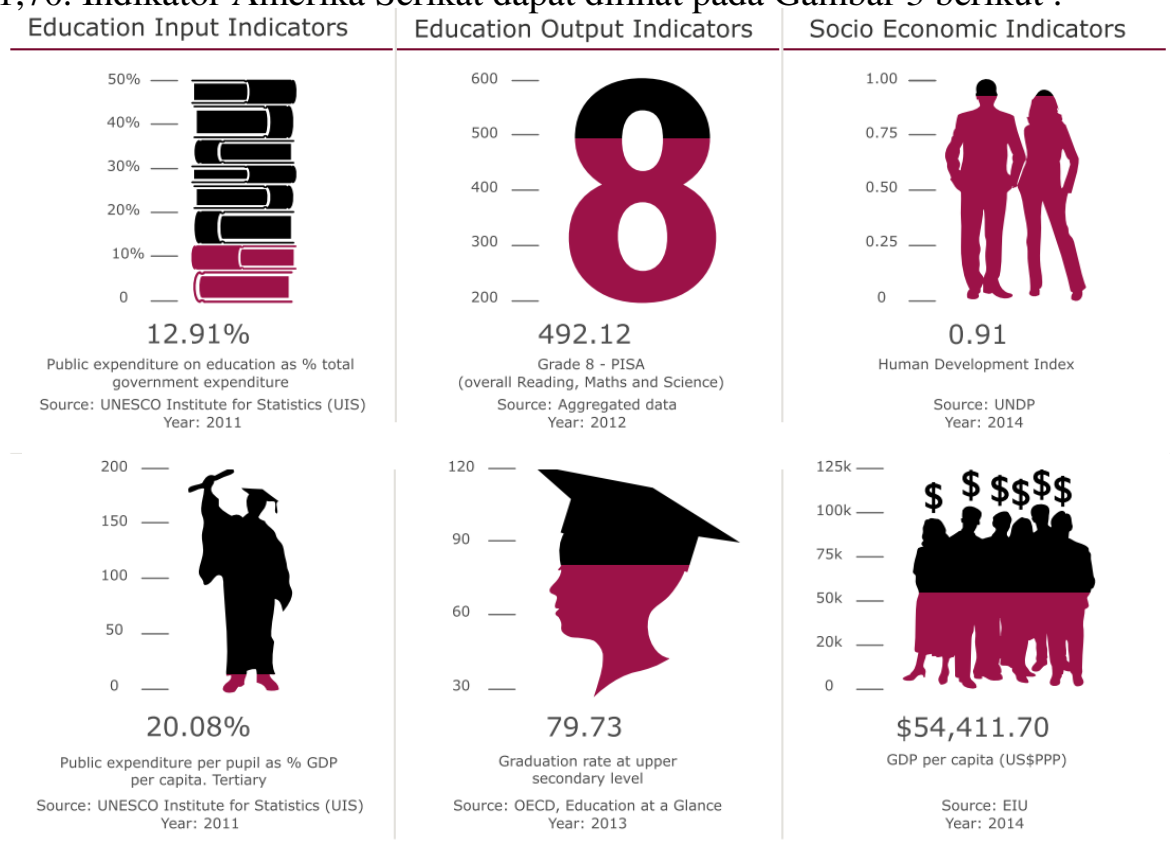

Gambar 3. Profil Negara Amerika Serikat (Sumber : The Learning Curve - Pearson PLC) 
Berdasarkan data di atas (Gambar 2 dan Gambar 3) maka dapat dilihat perbandingan bahwa negara dengan alokasi pengeluaran yang besar secara tidak langsung dapat membantu untuk mengembangkan sistem pendidikan yang baik meskipun memiliki GDP (Gross Domestic Product) yang lebih kecil daripada negara besar yang lain sebagai contoh perbandingan Korea Selatan dan Amerika Serikat.

Dalam referensi yang lain, kualitas sistem pendidikan suatu negara salah satunya dapat dilihat dari Global Competitiveness Index (GCI) karena dalam pengukurannya salah satunya berisi indikator Basic Requirements SubIndex - Health and Primary Education dan Efficiency Enhancers SubIndex - Higher education and trainings meskipun dalam berbagai kasus setiap negara mempunyai kebijakan negara masing - masing untuk menentukan prioritas terhadap pendidikan.

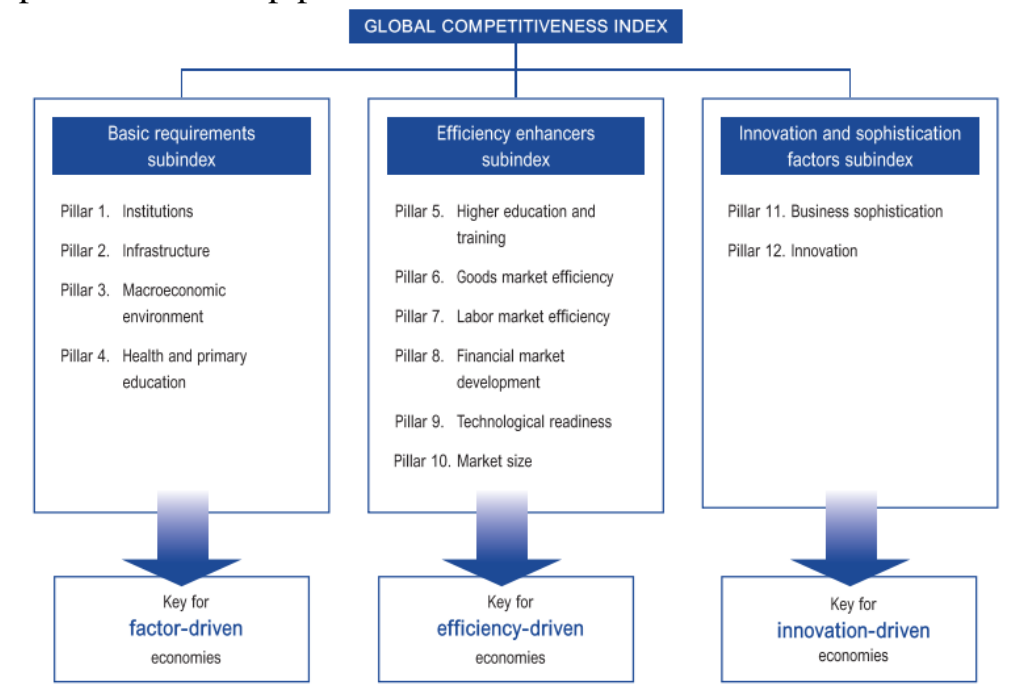

Gambar 4. Global Competitiveness Index

(Sumber : The Global Competitiveness Report 2015-2016)

Dari GCI terhadap tingkat pendidikan negara di dunia dapat dilihat bahwa kualitas pendidikan tidak berlaku sifat exponential growth dimana negara dengan tingkat ekonomi yang terbaik juga otomatis memiliki kualitas sistem pendidikan yang terbaik pula meskipun mereka mempunyai kemampuan lebih dalam hal alokasi dana pendidikan lebih. Berikut gambaran tingkat GCI beberapa negara di dunia dapat dilihat pada Gambar 5.

\begin{tabular}{|c|c|c|c|c|c|c|c|c|c|c|c|c|}
\hline \multirow[b]{2}{*}{ Country/economy } & \multirow[b]{2}{*}{$\begin{array}{l}\text { Cverall } \\
\text { GCl }\end{array}$} & \multicolumn{11}{|c|}{ INDICATORS } \\
\hline & & $\begin{array}{c}5.03 \\
\text { Quality } \\
\text { of the } \\
\text { education } \\
\text { system } \\
\end{array}$ & $\begin{array}{c}5.08 \\
\text { Extent } \\
\text { of } \\
\text { staff training }\end{array}$ & $\begin{array}{l}5.04 \\
\text { Quality of } \\
\text { math and } \\
\text { science } \\
\text { education }\end{array}$ & $\begin{array}{c}12.06 \\
\text { Availability } \\
\text { of scientists } \\
\text { and engineers }\end{array}$ & $\begin{aligned} & 7.07 \\
& \text { Reliance on } \\
& \text { s. proffessional } \\
& \text { ts management }\end{aligned}$ & $\begin{array}{c}7.06 \\
\text { Pay and } \\
\text { productivity }\end{array}$ & $\begin{array}{l}7.03 \\
\text { Hiring and } \\
\text { firing practices }\end{array}$ & $\begin{array}{c}7.01 \\
\text { Cooperation } \\
\text { in labor- } \\
\text { employer } \\
\text { selations } \\
\text { ren }\end{array}$ & $\begin{array}{c}7.02 \\
\text { Flexbility } \\
\text { of wage } \\
\text { detetermination }\end{array}$ & $\begin{array}{c}7.08 \\
\text { Country } \\
\text { capacity to } \\
\text { retain talent }\end{array}$ & $\begin{array}{c}7.09 \\
\text { country } \\
\text { capacity to } \\
\text { attract talent }\end{array}$ \\
\hline Switzerland & 1 & 1 & 1 & 4 & 23 & 6 & 4 & 2 & 1 & 16 & 1 & 1 \\
\hline Singapore & 2 & 3 & 4 & 1 & 11 & 5 & 3 & 4 & 3 & 6 & 6 & 2 \\
\hline United States & 3 & 18 & 14 & 44 & 4 & 9 & 8 & 10 & 31 & 19 & 2 & 6 \\
\hline Germany & 4 & 10 & 13 & 16 & 15 & 15 & 13 & 107 & 20 & 132 & 13 & 19 \\
\hline Netherlands & 5 & 8 & 9 & 7 & 22 & 4 & 46 & 89 & 8 & 131 & 11 & 13 \\
\hline Japan & 6 & 27 & 6 & 9 & 3 & 18 & 14 & 123 & 5 & 7 & 29 & 78 \\
\hline United Kingdom & 10 & 21 & 21 & 46 & 18 & 12 & 21 & 11 & 21 & 15 & 9 & 4 \\
\hline France & 22 & 30 & 28 & 19 & 19 & 29 & 59 & 127 & 116 & 69 & 63 & 42 \\
\hline Ireland & 24 & 9 & 20 & 21 & 9 & 7 & 7 & 19 & 15 & 56 & 19 & 9 \\
\hline Korea, Rep. & 26 & 66 & 36 & 30 & 40 & 37 & 24 & 115 & 132 & 66 & 25 & 35 \\
\hline Estonia & 30 & 34 & 32 & 14 & 73 & 25 & 10 & 13 & 28 & 1 & 93 & 86 \\
\hline Spain & 33 & 85 & 104 & 84 & 16 & 49 & 115 & 121 & 84 & 97 & 94 & 98 \\
\hline Italy & 43 & 65 & 132 & 41 & 26 & 119 & 131 & 132 & 127 & 134 & 113 & 115 \\
\hline Greece & 81 & 114 & 91 & 61 & 6 & 101 & 103 & 91 & 107 & 115 & 111 & 131 \\
\hline
\end{tabular}

Gambar 5. Performansi tingkat ekonomi ditinjau dari sumber daya manusia (Sumber : The Global Competitiveness Report 2015-2016) 


\section{SISTEM PENDIDIKAN DI KOREA SELATAN}

Pendidikan di Korea Selatan dilaksanakan dalam beberapa jenjang, yaitu jenjang pendidikan primer (primary education), pendidikan sekunder (secondary education), dan pendidikan tinggi (high educationa). Pembagian jenjang pendidikan didasarkan usia peserta didik. Korea Selatan berdasarkan data yang dijabarkan oleh The Learning Curve Pearson PLC pada tahun 2014 menduduki peringkat 1 (selengkapnya lihat Tabel 1). Adapun pencapaian negara Korea Selatan sebagai sistem pendidikan nomor 1 jika dilihat dari data secara tidak langsung dipengaruhi oleh perhatian pemerintah Korea Selatan terhadap bidang pendidikan penyediaan anggaran pendidikan yang besar melalui alokasi anggaran pendidikan. Anggaran yang dialokasikan oleh Korea Selatan selain digunakan untuk menjaminkan infrastruktur pendidikan baik dalam pembangunan fisik maupun non fisik tetapi juga memberikan perhatian lebih terhadap tenaga pengajar.

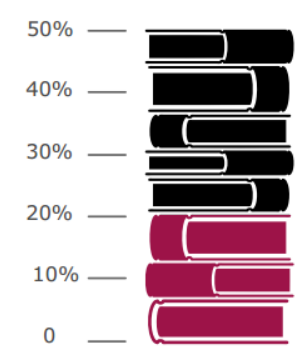

$20.27 \%$

Public expenditure on education as $\%$ total government expenditure Source: UNESCO Institute for Statistics (UIS) Year: 1998

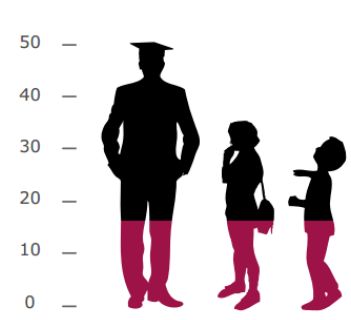

16.85

$$
\text { Pupil-teacher ratio. Primary }
$$

Source: UNESCO Institute for Statistics (UIS)
Year: 2014

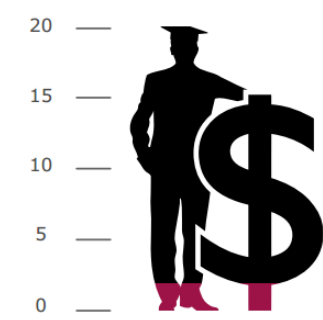

1.86

Teacher salary at primary, lower and upper secondary levels over the avg. gross wage Source: EIU based on OECD and EIU data
Year: 2013

Gambar 6. Indikator input bahasan pendidikan Korea Selatan

(Sumber : Sumber : The Learning Curve - Pearson PLC)

Dari Gambar 6, dapat dilihat bahwa untuk mendukung sistem pendidikan di Korea Selatan, pemerintah Korea Selatan mengalokasikan untuk dana pendidikan sebesar $20,27 \%$ dari total pengeluaran pemerintah. Hal tersebut ditunjang pula dengan rasion jumlah guru dan murid sebesar 16,85.

\section{Gambaran pendidikan Korea Selatan}

Sistem pendidikan di Korea Selatan menggunakan umur, bukan lewat pengetahuan, nilai, ataupun tes. Selain dilihat dari faktor umur (usia), faktor bulan kelahiran juga menentukan. Struktur pendidikan di Korea Selatan berformasi sama dengan yang ada di Indonesia (Riyana, 2008), yakni:

- 6 tahun untuk sekolah dasar (SD)

- 3 tahun untuk sekolah menengah pertama (SMP)

- 3 tahun untuk sekolah menengah atas (SMA)

- dan (meneruskan) universitas

Sedangkan untuk tahun pelajaran di bagi menjadi dua semester :

- Semester I : awal Maret - pertengahan Juli

- Liburan musim panas : pertengahan Juli - akhir Agustus

- Semester II : akhir Agustus - pertengahan Februari

- Liburan musim dingin : akhir Desember - awal Februari

- Ujian semester II dan kelulusan : awal Februari - pertengahan Februari (satu minggu)

- Liburan pendek : pertengahan Februari - awal Maret 
Sistem pendidikan dasar di Korea Selatan secara detail dapat dilihat pada keterangan berikut :

- Taman Kanak-kanak (TK)

Di Korea Selatan, TK bukanlah program publik / formal tetapi merupakan lembaga swasta yang mengajarkan bahasa Korea dan Inggris. Usia anak-anak yang memasuki TK berkisar antara 3-7 tahun. Nah, di TK ini satu kelas bisa berisi anak-anak dengan rentang umur yang berbeda (4 tahun).

- Sekolah Dasar (Chodeunghakgyo)

Sekolah dasar terdiri dari kelas $1-6$ dengan rentan usia 7 - 13 tahun. Siswa kelas 1 dan 2 mempelajari bahasa Korea, matematika, sains, ilmu sosial, seni, dan bahasa Inggris, sedangkan kelas 3 hingga 6 ditambah pendidikan moral, seni praktis, dan musik.

\section{Sistem Pendidikan di Korea Selatan}

Secara umum sistem pendidikan di Korea Selatan terdiri dari empat jenjang (Riyana, 2008) yaitu : Sekolah dasar, Sekolah Menengah Tingkat Pertama, SLTA dan pendidikan tinggi. Keempat jenjang pendidikan ini sejalan dengan tingkat $1-6$ (SD), grade 7 - 9 (SLTP), 10 -12 (SLTA), dan grade 13 - 16 (pendidikan tinggi/program S1) serta program pasca sarjana (S2/S3). Berikut visualisasi tingkat pendidikan

1. Sekolah dasar merupakan pendidikan wajib selama 6 tahun bagi anak usia 6 dan 11 tahun, dengan jumlah lulusan SD mencapai 99,8\%, dan putus sekolah SD $0,2 \%$.

2. SMP merupakan kelanjutan SD bagi anak usia 12-14 tahun, selama 3 tahun pendidikan.

3. Kemudian melanjutkan ke SLTA pada grade 10-11 dan 12, dengan dua pilihan yaitu: umum dan sekolah kejuruan. Sekolah kejuruan meliputi pertanian, perdagangan, perikanan dan teknik. Selain itu ada sekolah komperhensif yang merupakan gabungan antara sekolah umum dan sekolah kejuruan, yang merupakan bekal untuk melanjutkan ke akademik (Junior College) atau universitas (Senior College).

4. Pendidikan tinggi/akademik (Junior College) atau universitas program S1 (senior college), pada grade 13-16, dan selanjutnya ke program pasca sarjana (graduate school) gelar master/doktor.

Salah satu keputusan Dewan Nasional Republik Korea tahun 1948 adalah menyusun undang-undang pendidikan. Sehubungan dengan hal ini, maka tujuan pendidikan Korea Selatan (Riyana, 2008) adalah sebagai berikut :

1. Menanamkan pada setiap orang rasa Identitas Nasional dan penghargaan terhadap kedaulatan Nasional

2. Menyempurnakan kepribadian setiap warga Negara

3. Mengemban cita-cita persaudaraan yang universal mengembangkan kemampuan untuk hidup mandiri dan berbuat untuk Negara yang demokratis dan kemakmuran seluruh umat manusia

4. Menanamkan sifat patriotisme.

Dalam pengembangan kurikulum, Negara Korea Selatan membagi menjadi tiga jenjang yaitu jenjang pendidikan primer (primary education), pendidikan sekunder (secondary education), dan pendidikan tinggi (high education). Adapun jenjang pendidikan secara detail (Rochmah, 2015) dijelaskan sebagai berikut : 
- Pendidikan primer

Jenang pendidikan primer di Korea Selatan diwajibkan untuk anak-anak berusia 6 sampai dengan 14 tahun. Pada jenjang pendidikan primer ini, prosesnya dilaksanakan di taman kanak-kanak dan sekolah dasar.

- Pendidikan sekunder

Pendidikan sekunder di Korea Selatan dilaksanakan selama 6 tahun, yaitu 3 tahun di sekolah menengah (setara dengan SMP di Indonesia) dan sekolah atas (setara dengan SMA di Indonesia).

\section{- Pendidikan tinggi}

Pendidikan tinggi di Korea Selatan dilaksanakan melalui kegiatan-kegiatan perkuliahan di beberapa perguruan tinggi, baik perguruan tinggi negeri maupun swasta yang jumlahnya sekitar 330 perguruan tinggi. Adapun beberapa perguruan tinggi yang terkemuka di Korea Selatan antara lain Universitas Korea (Korea University), Universitas Nasional Seoul (Seoul National University), Universitas Ewha (Ewha Women's University), dan Universitas Yonsei (Yonsei University).

Sistem pendidikan di negara Korea Selatan tidak lepas dari treatment yang dilakukan. Berikut adalah treatment - treatment yang dapat dijadikan pertimbangan :

- Taman kanak-kanak "Youchiwon" dimulai usia 3 tahun hingga 6 tahun. Pada tahap pra sekolah swasta pemerintah tetap membantu, mengawasi dan memperhatikan sepenuhnya pengolahan sekolah-sekolah TK ini.

- Adanya keterkaitan pertumbungan ekonomi dengan perkembangan pendidikan. Adanya investasi pemerintah pada bidang pendidikan mendorong kebijakan ekonomi dalam hal perkembangan industry. Industri tersebut kemudian menjadi mesin ekonomi yang efektif karena perkembangannya disesuaikan dengan ketersediaan tenaga kerja yang dihasilkan oleh sistem pendidikan.

- Sekolah negeri dan swasta pra sekolah memiliki program pendidikan yang sama, yaitu lebih banyak mengajarkan kemandirian, kreatifitas dan bersosialisasi dengan lingkungan dan mengajarkan tentang kehidupan sehari-hari. Pada tahap pra SD , calon murid diajak terlebih dahulu untuk melihat lingkungan seolah selanjutnya.

- Pendidikan korea Selatan dilakukan dengan sangat keras karena ada penanaman displin dalam pelaksanaannya sehingga terkadang siswa masuk sekolah jam 8 pagi sampe tengah malam karena selepas sekolah formal mereka mengambil sekolah non formal untuk menambah keahlian-keahlian lainnya.

\section{SISTEM PENDIDIKAN DI JEPANG}

Perkembangan pendidikan di Jepang secara tidak langsung dipengaruhi oleh perkembangan kebudayaan Jepang, tentang bagaimana masyarakat Jepang berhasil berkembang dari tradisional menjadi masyarakat industri modern. Hal tersebut terjadi karena masyarakat Jepang mampu untuk beradaptasi dan mempunyai kemampuan untuk bertahan terhadap perubahan zaman. Dalam perkembangannya, masyarakat Jepang melakukan reformasi dan mempersiapkan diri dari datangnya pengaruh kebudayaan lain. Masyarakat Jepang dikenal sebagai masyarakat yang berhasil berkembang dari tradisional menjadi masyarakat industri modern dengan caranya sendiri. Keberhasilan Jepang disebabkan keberhasilan adaptasi terhadap model - model pembaharuan yang berasal dari luar dan kondisi masyarakat Jepang yang berusia ribuan tahun memiliki kekuatan kekuatan yang memungkinkan untuk survival, bahkan manjadi masyarakat modern berkategori kelas satu di dunia. Dari kemampuan di atas maka masyarakat Jepang diketahui dengan ciri- ciri sebagai berikut (Dimyati, 1988) :

a. Kemauan yang kuat untuk mempelajari hal-hal baru dan menitu hal-hal yang dapat mengembangkan kebudayaan Jepang. 
b. Mengagumi ide - ide asing dengan cermat memilih hal-hal yang dapat diterima sesuai dengan kondisi Jepang.

c. Menghargai kecakapan dan prestasi seseorang lebih tinggi daripada latar belakang atau keturunan.

Ciri - ciri tersebut di atas membuat Negara Jepang untuk dapat bergerak lebih cepat dalam pengembangan pendidikan. Selain itu, tradisi kesusasteraan, filsafat, penggunaan bahasa tulis, bebas buta huruf, dan kegemaran belajar mengetahui di semua lapisan masyarakat mempermudah Jepang untuk transformasi.

Berdasarkan data yang dikemukakan The Learning Curve - Pearson PLC pada tahun 2014, negara Jepang menduduki urutan ke 2 dalam pengembangan sistem pendidikannya. Gambar 7 di bawah ini menggambarkan bahwa pemerintah Jepang memberikan perhatian terhadap pendidikan dengan memberikan alokasi dana pendidikan sebesar 9,58\% dari total pengeluaran negara per tahun dan rasio pengajar terhadap peserta didik sebesar 17,09. Alokasi dana pendidikan tersebut digunakan untuk melakukan pembangunan pendidikan di negara Jepang.

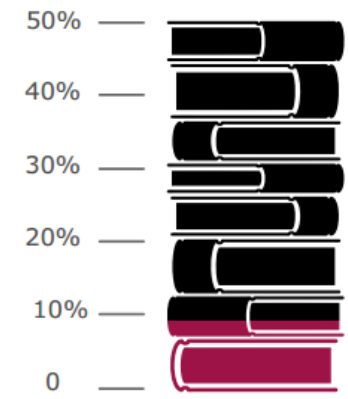

\section{$9.58 \%$}

Public expenditure on education as \% total government expenditure Source: UNESCO Institute for Statistics (UIS) Source: UNESCO Institute for Statistics (UIS)
Year: 2013 Year: 2013

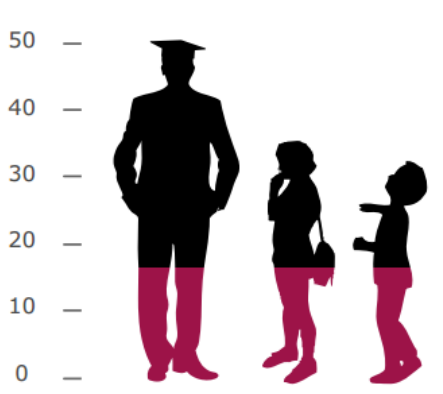

17.09

Pupil-teacher ratio. Primary

Gambar 7. Indikator input bahasan pendidikan Jepang

(Sumber : The Learning Curve - Pearson PLC)

\section{Gambaran pendidikan Jepang.}

Masyarakat Jepang merupakan masyarakat yag maju dan berkembang pesat di berbagai bidang kehidupan seperti ekonomi, teknologi, politik, pendidikan, kesenian, olah raga dan komunikasi massa. Kemajuan Jepang yang begitu pesat membuat Jepang sering dijadikan salah satu studi perbandingan. Salah satu hasil studi perbandingan adalah yang dilakukan oleh Amerika Serikat (William K. Cummings, Erward R Beauchamp) dan Jepang (Shago Ichikawa, Victor N. Kobayashi, Morkazt Ushiogi) menunjukkan hasil studi perbandingan di bidang pendidikan (Dimyati,1988) sebagai berikut :

a. Masyarakat Jepang memiliki tradisi kuat yang berupa keinginan luar biasa untuk belajar dengan kebudayaan lain, memilih dan mengadaptasinya untuk mengembangkan kebudayaan sendiri.

b. Masyarakat Jepang berpendapat bahwa hanya dengan belajar , orang dapat memperbaiki kehidupan individual maupun masyarakat.Guru-guru Jepang memiliki tanggung jawab yang besar dan mendalam terhadap keberhasilan belajar siswa. Sistem social pendidikan Jepang selalu beriklim mendorong kerja keras terhadap 3 faktor kunci keberhasilan murid, guru dan orang tua. Adanya peranan orang tua untuk memelihara kualitas pendidikan anaknya dengan mendorong keberhasilan anaknya memasuki sekolah yang baik. 
c. Kewajiban belajar, sistem ujian, standard nasional yang uniform menghasilkan kekayaan sumber daya penduduk yang terlatih baik.

d. Waktu belajar di sekolah Jepang sejumlah 240 hari tiap tahun, jika dibandingkan dengan Amerika Serikat sejumlah 180 hari per tahun.

e. Sekolah Jepang mendidik tentang pentingnya Self Discipline, etik kerja keras.

f. Masyarakat Jepang memanfaatkan media massa untuk meningkatkan budaya belajar masyarakat. Media massa berupa buku teks, surat kabar, majalah, radio, televisi digunakan untuk meningkatkan mutu pendidikan sekolah dan pendidikan sosial.

Peraturan pendidikan di Jepang dapat dibedakan dalam dua periode (Achmad dan Shobahiya, 2008), yaitu sebelum dan sesudah perang Dunia II. Sebelum perang, kebijakan pendidikan yang berlaku adalah Salinan Naskah Kekaisaran tentang Pendidikan (Imperial Rescript on Education). Dinyatakan bahwa para leluhur kaisar terdahulu telah membangun kekaisaran dengan berbasis pada nilai yang luas dan kekal, serta menanamkannya secara mendalam dan kokoh. Materi pelajarannya dipadukan dalam bentuk kesetiaan dan kepatuhan dari generasi ke generasi yang menggambarkan keindahannya. Itulah kejayaan dari karakter kaisar, dan ia juga telah mengendalikannya dengan sumber-sumber berpendidikan. Pendidikan hendaknya mampu mengafiliasikan seseorang kepada orang tuanya, suami isteri secara harmoni, sebagai sahabat sejati, menjadi diri sendiri yang sederhana dan moderat, mencurahkan kasih sayang kepada semua pihak, serta menuntut ilmu dan memupuk seni. Sedangkan pada periode sesudah perang, mulai 3 November 1946, konstitusi baru Jepang menetapkan kebijakan pendidikannya atas dasar hak asasi manusia, jaminan kebebasan berpikir, dan hati nurani, kebebasan beragama, kebebasan akademik, dan hak bagi semua orang untuk mendapatkan pendidikan sesuai dengan kemampuan mereka.

Pada Maret 1947, melalui Peraturan Pendidikan Nasional (School Education Law) ditetapkan susunan dasar pendidikan keseluruhan atas dasar 6-3-3-4 beserta tujuan khusus pada tiap jenjangnya. Menurut Abd. Rachman Assegaf (2003) dalam Achmadi dan Mahasri Shobahiya (2008), pada Maret 1947 mulai berlaku. Hukum Dasar Pendidikan (Fundamental Law of Education) yang pada hakekatnya merupakan statement filsafat pendidikan demokratis yang dalam banyak hal berbeda dengan Imperial Rescript on Education. Misalnya, dalam hubungan antara warga dengan Negara.

Dalam Imperial Rescript on Education disebutkan bahwa "Setiap warga memiliki kewajiban untuk mengembangkan daya intelektual dan moral mereka, melaksanakan hukum dan mempersembahkan keberaniannya deminegara untuk melindungi dan menjaga kesejahteraan istana kaisar". Sedangkan dalam Fundamental Law of Education disebutkan bahwa, "Setiap warga memiliki kesempatan yang sama menerima pendidikan menurut kemampuan mereka, bebas dari diskriminasi atas dasar ras, jenis kelamin, status sosial, posisi ekonomi, asal usul keluarga, bantuan finansial, bagi yang memerlukan, kebebasan akademik, dan tanggung jawab untuk membangun negara dan masyarakat yang damai". Perbedaan yang lain adalah mengenai tujuan pendidikan. Dalam Imperial Rescript on Education disebutkan bahwa tujuan pendidikan adalah untuk meningkatkan kesetiaan dan ketaatan bagi Kaisar agar dapat memperoleh persatuan masyarakat di bawah ayah yang sama, yakni Kaisar. Adapun tujuan pendidikan menurut Fundamental Law of Education adalah untuk meningkatkan perkembangan kepribadian secara utuh, menghargai nilai-nilai individu, dan menanamkan jiwa yang bebas. 


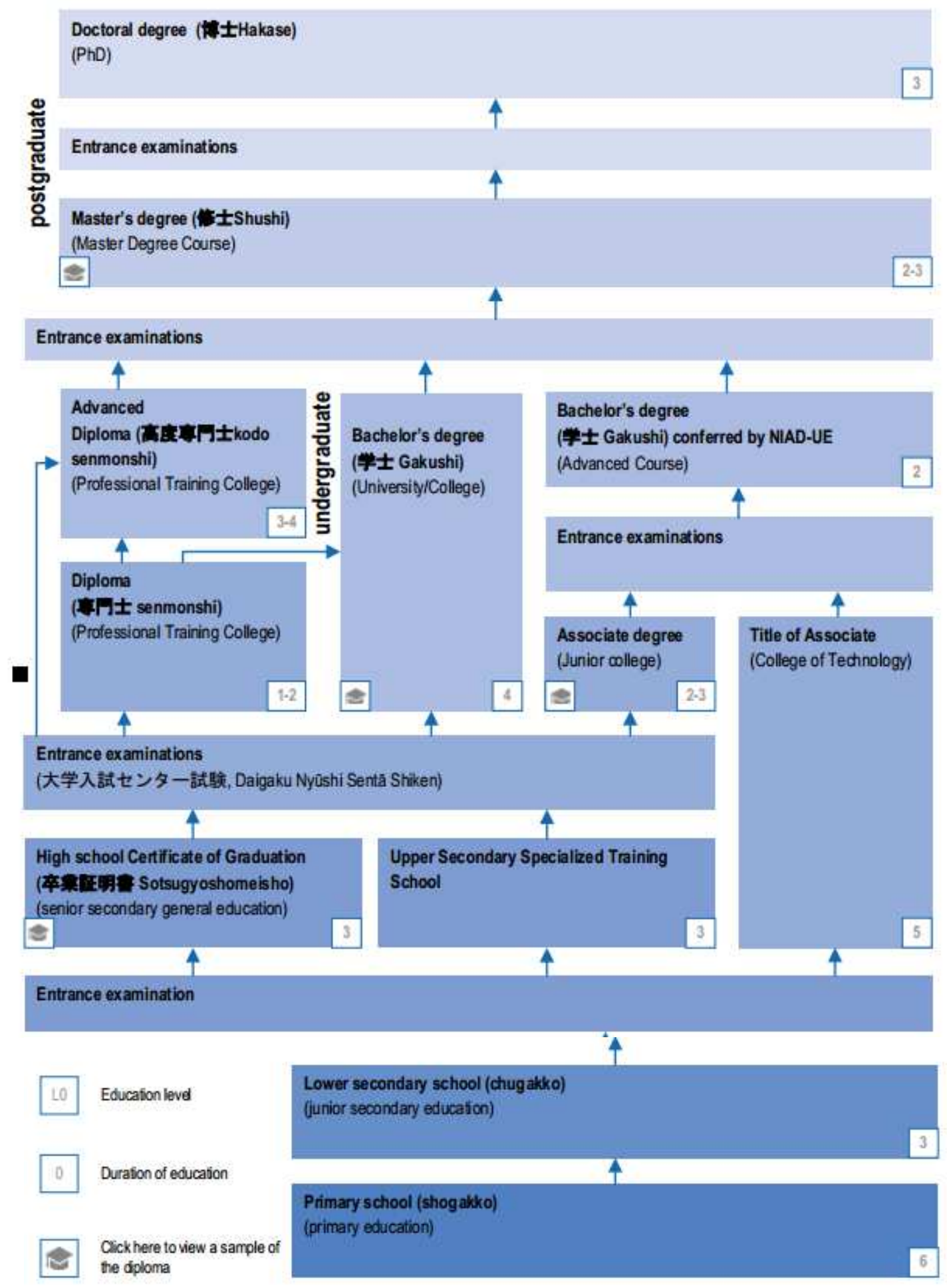

Gambar 8. Sistem pendidikan Jepang

(Sumber :Education System Jepang, 2015) 
Sedangkan struktur pendidikan Jepang berdasarkan rentang umur dapat dilihat Gambar 9 berikut :

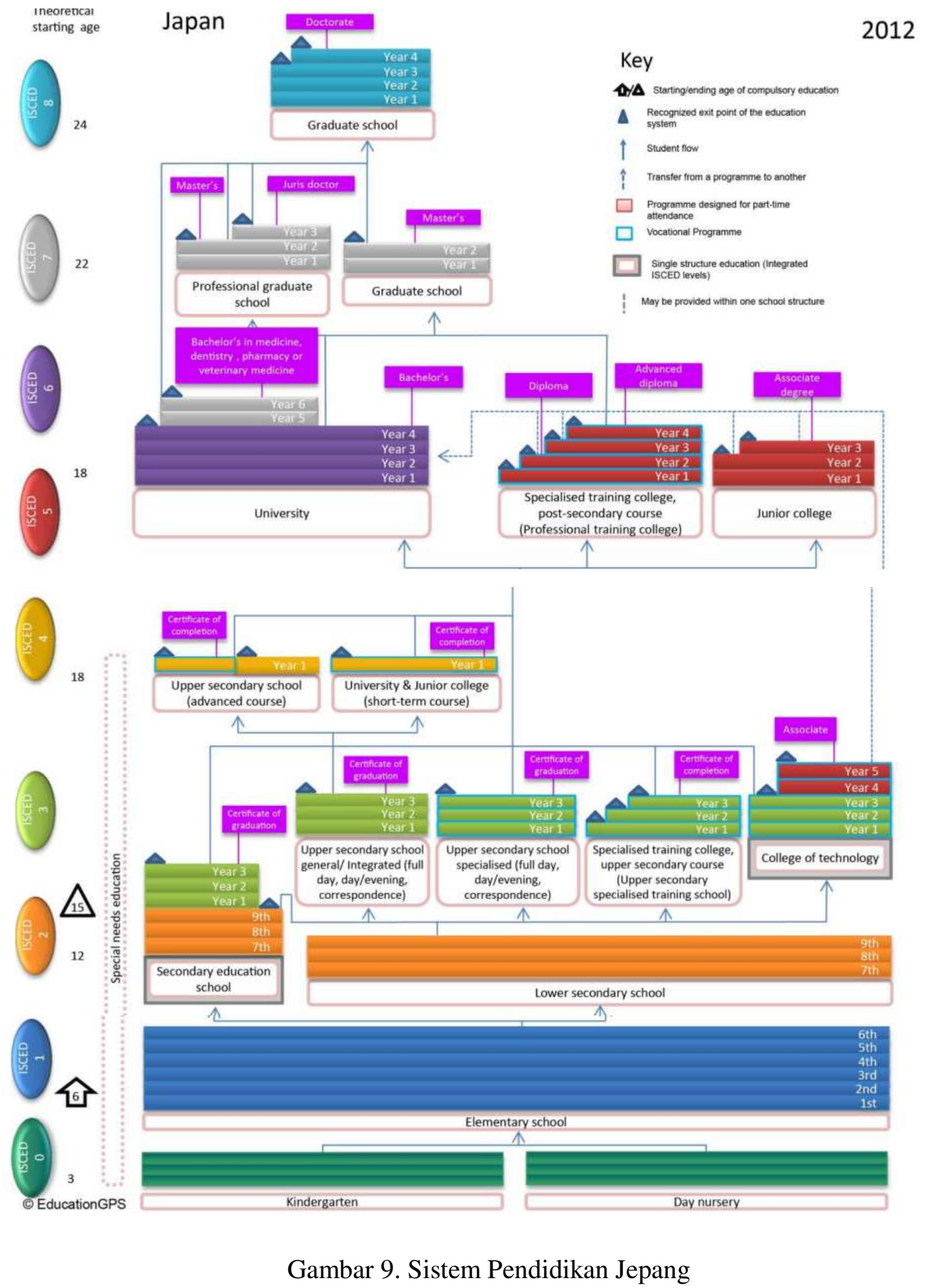

(Sumber : EDUCATION POLICY OUTLOOK: JAPAN @ OECD 2015)

Konstitusi Jepang menetapkan kebijakan pendidikan dasar nasional, sebagai berikut: "All people shall have the right to receive an equal education corresponding to their ability, as provided by law. The people shall be obligated to have all boys and girls under their protection receive ordinary education as provided for by law. Such compulsory education shall be free.". Dasar UU Pendidikan, yang diundangkan dan diberlakukan Maret 1947, menetapkan secara lebih rinci tujuan dan prinsip-prinsip pendidikan sesuai dengan semangat Konstitusi. Di dalamnya ditetapkan prinsip-prinsip tertentu nasional pendidikan: kesempatan yang sama, wajib belajar, pendidikan sekolah, 
pendidikan sosial, larangan pendidikan politik partisan, larangan pendidikan agama untuk agama tertentu di sekolah-sekolah umum nasional dan lokal dan larangan kontrol yang tidak tepat pendidikan.

Namun demikian, keadaan sekitar pendidikan telah banyak berubah dalam hal seperti kemajuan ilmu pengetahuan dan teknologi, teknologi informasi canggih, internasionalisasi, penuaan masyarakat dengan jatuhnya angka kelahiran, dan gaya hidup keluarga. Pada saat yang sama, lingkungan sekitar anak-anak telah berubah secara signifikan, dan berbagai masalah telah. Mengingat keadaan seperti itu, Undang-Undang Dasar Pendidikan yang ada benar-benar direvisi dan revisi UU disahkan pada tanggal 15 Desember 2006. Revisi undang-undang jelas mengatur prinsip-prinsip pendidikan yang dianggap sangat penting saat ini sementara pada saat yang sama mewarisi prinsip-prinsip universal yang diatur dalam undang-undang sebelumnya. Adapun prinsip-prinsip pendidikan di Jepang (Ilmu Pendidik, 2015) adalah sebagai berikut:

1. Legalisme : Pendidikan di Jepang tetap mengendepankan aturan hukum dan melegalkan hak setiap individu untuk memperoleh pendidikan tanpa mendiskriminasikan siapapun, suku, agama, ras, dan antar golongan berhak mendapatkan pendidikan yang layak.

2. Adminstrasi yang Demokratis : Negara memberikan kesempatan kepada siapa saja untuk memperoleh pendidikan dengan biaya yang masih terjangkau oleh masyarakatnya. Biaya pendidikan Jepang di usahakan untuk bisa dijangkau sesuai keuangan masyarakatnya, memberikan beasiswa bagi siswa yang berprestasi ataupun kurang mampu.

3. Netralitas : Pendidikan Jepang diberikan kepada setiap siswa dengan tingkat pendidikan masing-masing dengan mengedepankan pandangan persamaan derajat setiap siswanya tanpa membeda-bedakan latar belakang materil, asal-usul keluarga, jenis kelamin, status sosial, posisi ekonomi, suku, agama, ras, dan antar golongan.

4. Penyesuaian dan penetapan kondisi pendidikan : Dalam proses pengajaran memiliki tingkat kesulitan masing-masing yang disesuaikan dengan tingkatantingkatan pendidikan yang ditempuh.

5. Desentralisasi : Penyebaran kebijakan-kebijakan pendidikan dari pemerintah pusat secara merata kepada seluruh sekolah yang ada dinegara tersebut sehingga perkembangan dan kemajuan sistem pendidikan sehingga dapat diikuti dengan baik.

Tujuan pendidikan di Jepang adalah "Pendidikan harus bertujuan untuk pengembangan penuh kepribadian dan berusaha untuk memelihara warga, suara dalam pikiran dan tubuh, yang dijiwai dengan kualitas yang diperlukan bagi mereka yang membentuk negara dan masyarakat yang damai dan demokratis."

Tujuan-tujuan yang menjadi target yang ingin dicapai pendidikan Jepang yaitu :

1. Pencapaian pengetahuan luas dan budaya, budidaya sensibilitas kaya dan rasa moralitas, dan pengembangan tubuh yang sehat.

2. Pengembangan kemampuan individu, membina semangat otonomi dan kemandirian, dan menekankan hubungan antara karir dan kehidupan praktis.

3. Membina sikap menghargai keadilan dan tanggung jawab, saling menghormati dan kerjasama, kesetaraan antara laki-laki dan perempuan, dan jiwa sipil.

4. Membina sikap menghormati kehidupan dan alam, dan memberikan kontribusi terhadap perlindungan lingkungan.

5. Membina sikap menghormati tradisi dan budaya kita, mencintai negara dan wilayah yang mengasuh mereka, menghormati negara-negara lain, dan memberikan kontribusi bagi perdamaian dunia dan perkembangan masyarakat internasional. 


\section{Referensi}

Achmadi., Shobahiya, Mahasri. 2008. SISTEM PENDIDIKAN (Studi Komparasi antara Indonesia dan Jepang). Pascasarjana Universitas Muhammadiyah Surakarta.

Dimyati, Muhammad. 1988. Landasan Kependidikan. Departemen Pendidikan dan Kebudayaan. Direktorat Jenderal Pendidikan Tinggi. Jakarta : Proyek Pengembangan Lembaga Pendidikan Tenaga Kependidikan.

Education Policy Outlook. 2015. JAPAN Education System. OECD

Ilmu Pendidik. 2015. Tujuan dan Prinsip Pendidikan Negara Jepang. http://www.ilmupendidik.com/2015/05/tujuan-dan-prinsip-pendidikannegara.html. Diakses pada 5 Maret 2017.

Pearson. 2014. http://thelearningcurve.pearson.com/index/index-ranking. Diakses pada 19 Februari 2017.

Riyana, Cepi. 2008. Kurikulum Cina, Korea dan Jepang. Universitas Pendidikan Indonesia.

Rochmah , Afifatur. 2015. Sistem Pendidikan di Korea Selatan. http://pendidikannegarakorea.blogspot.co.id/2015/03/sistem-pendidikan-di-koreaselatan-add_10.html. Diakses pada 12 Maret 2017.

Rochman, Arif. 2010. Pendidikan Komparatif: Menuju Ke Arah Metode Perbandingan Pendidikan Antar Negara. Yogyakarta : Laksbang Grafika.

Schwab, Klaus., Sala-i-Martín, Xavier. 2015. The Global Competitiveness Report 2015-2016. Geneva : The World Economic Forum's Global Competitiveness and Risks.

Sinaga, Bornok. 2012. Pendidikan Dan Pembelajaran Yang Demokratis Dan Humanistis. Jurnal Generasi Kampus. Volume 5, Nomor 2, September 2012. ISSN 1978869X. 